\title{
HERITAGE HOUSE MAINTENANCE USING 3D CITY MODEL APPLICATION DOMAIN EXTENSION APPROACH
}

\author{
Zulaikha Hana Mohd ${ }^{1}$, Uznir Ujang ${ }^{1,2}$, Tan Liat Choon ${ }^{1}$ \\ ${ }^{1}$ Department of Geoinformation, Faculty of Geoinformation and Real Estate, \\ Universiti Teknologi Malaysia, 81310, Johor Bahru, Johor, Malaysia \\ eika_hanna@yahoo.com \\ mduznir@utm.my, tichoon@utm.my \\ ${ }^{2}$ Department of Geodesy, National Space Institute, \\ Denmarks Tekniske Universitet, DK-2800 Kongens. Lyngby, Copenhagen, Denmark \\ Ujang@space.dtu.dk
}

KEYWORDS : Heritage House, 3D City Model, Level of Details, CityGML, Extension of CityGML

\begin{abstract}
:
Heritage house is part of the architectural heritage of Malaysia that highly valued. Many efforts by the Department of Heritage to preserve this heritage house such as monitoring the damage problems of heritage house. The damage problems of heritage house might be caused by wooden decay, roof leakage and exfoliation of wall. One of the initiatives for maintaining and documenting this heritage house is through Three-dimensional (3D) of technology. 3D city models are widely used now and much used by researchers for management and analysis. CityGML is a standard tool that usually used by researchers to exchange, storing and managing virtual 3D city models either geometric and semantic information. Moreover, it also represent multi-scale of 3D model in five level of details (LoDs) whereby each of level give a distinctive functions. The extension of CityGML was recently introduced and can be used for problems monitoring and the number of habitants of a house .
\end{abstract}

\section{INTRODUCTION}

The conservation and protection of the heritage of tangible and intangible forms has earned an ever-increasing and vibrant international attention since the 20th century (Vecco. M, 2010). Digital representations of architectural are increasingly used in cultural heritage and being an essential tool to facilitate further analysis related to urban or environmental issues (H. RichardsRissetto and R. Plessing, 2015). Meanwhile, a detail representation of 3D city model is needed for some application such as heritage architecture, facility management and interior design (R. Akmaliaa et.al, 2014). The measurement tools that has the ability to generate the $3 \mathrm{D}$ model of building with fast and accurate with many method such as digital photogrammetry, laser scanning, Unmanned Aerial Vehicle (UAV) and others surveying techniqus (Basir.A et.al, 2014). The figures below show the 3D model result by using 3D software.

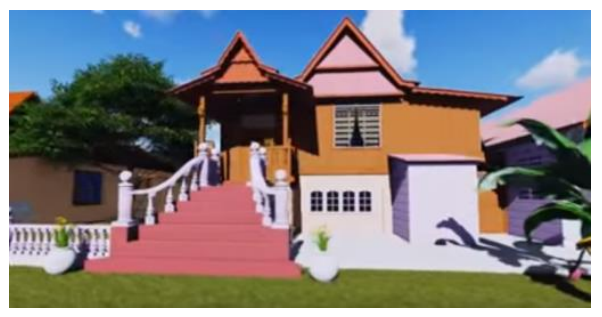

Figure 1: 3D model of heritage house in Kampung Morten using SketchUP, 3Dsmax and lumion6 (Safwan and Hariz, 2016)
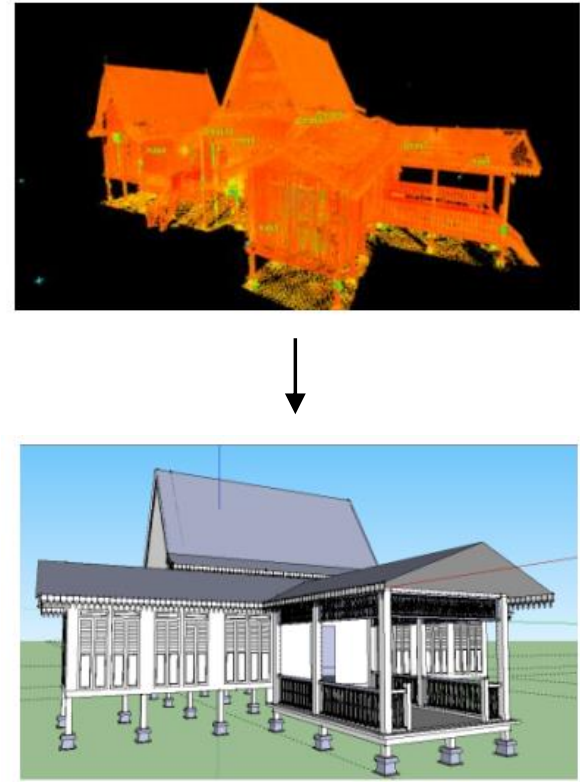

Figure 2 : 3D model of Kota Johor Lama Museum point cloud using Terrestrial Laser Scanning and construct in SketchUP ( Basir.A et.al, 2014) 


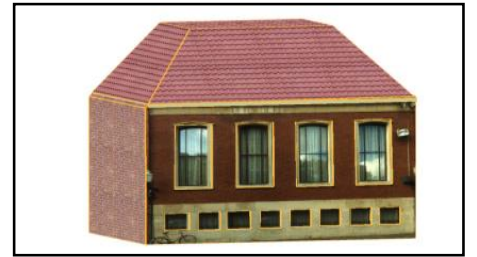

Figure 3 : 3D model of Holland Hall, University of Exeter using Aerial photogrammetry ( 3dwarehouse.sketchup.com, 2004)

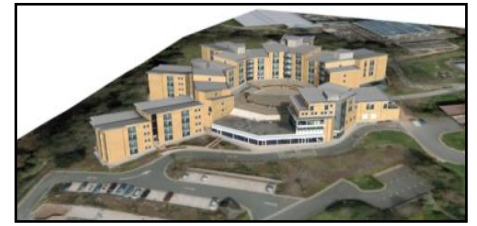

Figure $4:$ D model by Facade Image, (Shi Pu and George Vosselman, 2009)

3D models can be present in more detail by using Level of Details (LoDs) which is different scale of details and represent in CityGML . It can represent semantic, geometric, topology, and also appearance for virtual 3D city model base on field requirement. Then, CityGML information are stored and exchanged by GML schema and stored as a XML file. The attributes for surface models and some layers need to created to recognize building features. As example for LoD3, building opening like windows, doors and stairs should be created in different layers and the information saved in semantic information XML files. After all the LoD represent in CityGML, extending CityGML are the so-called Application Domain Extensions (ADE) which is the introduction of new properties to existing CityGML classes like management of cultural heritage, the definition of new feature classes for ancient house, maintenance of heritage houses and others. Extended CityGML instance documents can be validated against CityGML and each ADE scheme (T. H. Kolbe. 2009).

\section{METHODOLOGY}

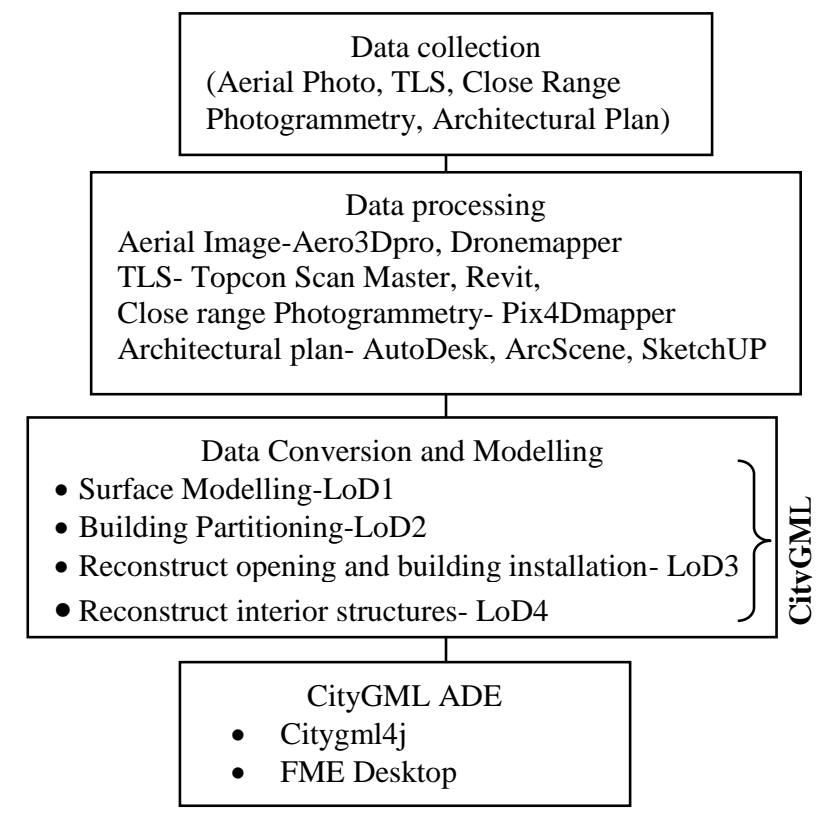

Figure 5 : Process from Data Collection untill CityGML ADE
Based on figure 5, there are many methods available for data collection. 3D data such as Aerial Photo, TLS, Close Range Photogrammetry and Architectural Plan. I. Nazrita et.al, (2009) said among all these technique, digital 3D laser scanning method has proved to produced. Researchers may make data processing base on data obtained. This process usually take a time to get the proper and quality modeling. Lately, CityGML always used to solve the problem in term of management and technical. CityGML also use in maintaining and preserve heritage site.

\section{LEVEL OF DETAILS (LODS)}

Researchers are trying to develop efficient and effective method to create 3D model but each methods has advantages and limitation (Surendra Pal Singh et.al, 2013). All the data must be process according to their respective methods, for example data collected using TLS will be processed using Smart Scan or Cyclone 7.3 that produce point cloud data and then converted into 3D software such as AutoCAD, Revit, Sketchup, and another 3D software. Then, the 3D model will be exchange.

The 3D models was converted into GML files for represent in any of an open source software such as LandXplorer. The layer were created as the attribute to give semantic information follow the CityGML file structure. Furthermore, LoD0 refer to building footprint, roof outline and 2.5D digital terrain model which is lower detail of model and useful for mapping and landscape planning. The highest LoD4 visualize the interior of building and more detail structure displayed. As example for refurbish heritage house, the high resolution textured 3D model need to use to check wood decay due to temites. Or introduces interior heritage house for tourism purpose to tourisst in which use the LoD4.

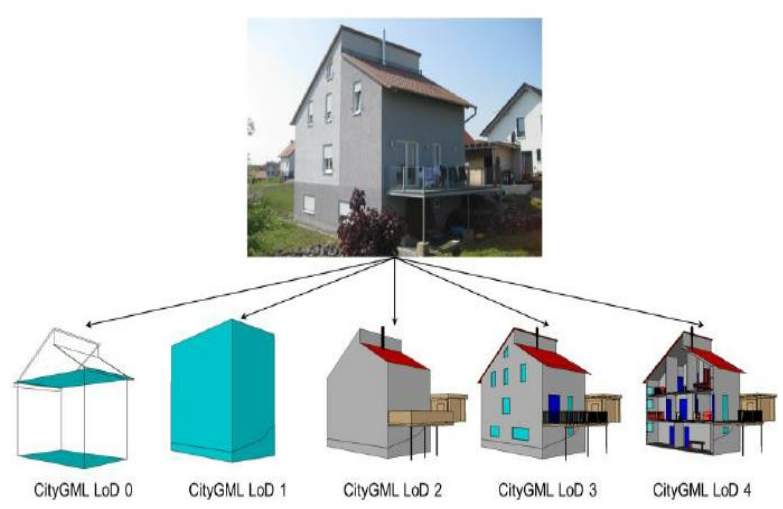

Figure 6 : Representation of a building using LoD0 - LoD4 (Löwner. M.-O, et.al, 2013)

Figure 7-9 shows the example of XML code for representing LoD1 (saved below the MultiSurface section without any building parts), LoD2 (WallSurface and RoofSurface) and LoD3 and LoD4 (Openings were created below the WallSurface section). 


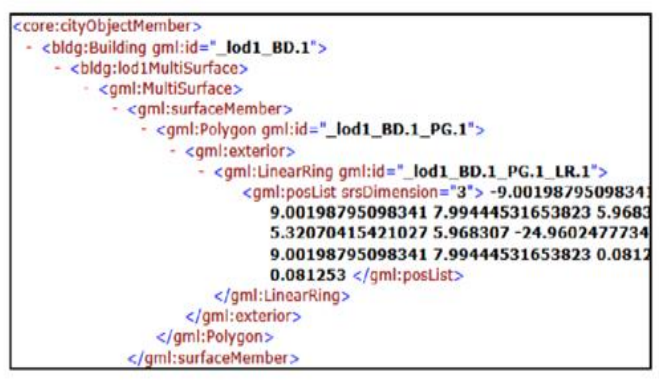

Figure 7 : Source code LoD1 (R. Akmaliaa et.al, 2014).

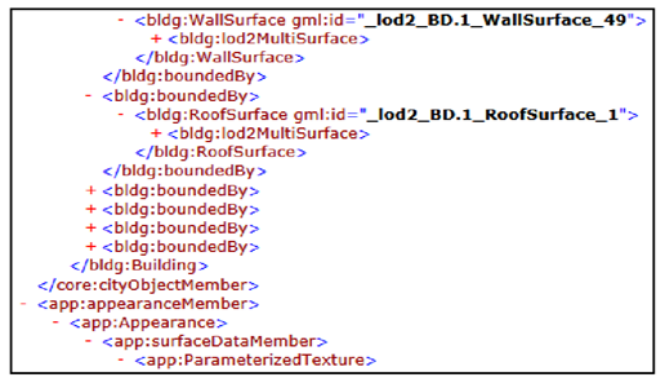

Figure 8 : Source code LoD2 (R. Akmaliaa et.al, 2014).

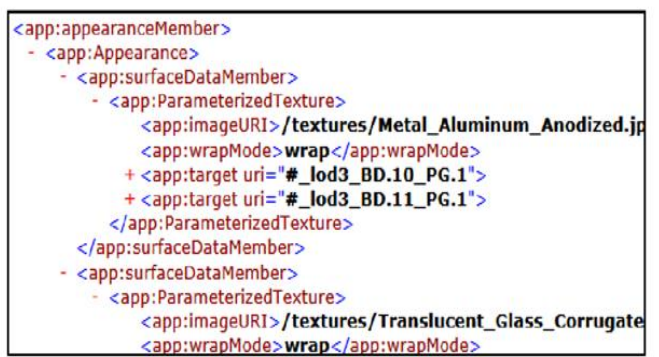

Figure 9 : Source code LoD3 (R. Akmaliaa et.al, 2014).

\section{EXTENDING CITYGML}

CityGML ADEs has to be defined within an extra XML schema definition file with its own namespace. The advantage of this approach is that the extension is formally specified. The ADE concept support two different methods which are the existing CityGML classes can be extended through additional attributes and in ADE schema, new classes can be derived from existing CityGML using generalization concept (Romain Nouvel et.al, 2015). Thus, the ADE can use for any management such as Noise ADE, Energy ADE, Solar ADE and also Heritage ADE. According to J.Finat et. al (2010), they create CityGML framework by adding three task to support the software application (GIRAPIM) for heritage and urban documentation.

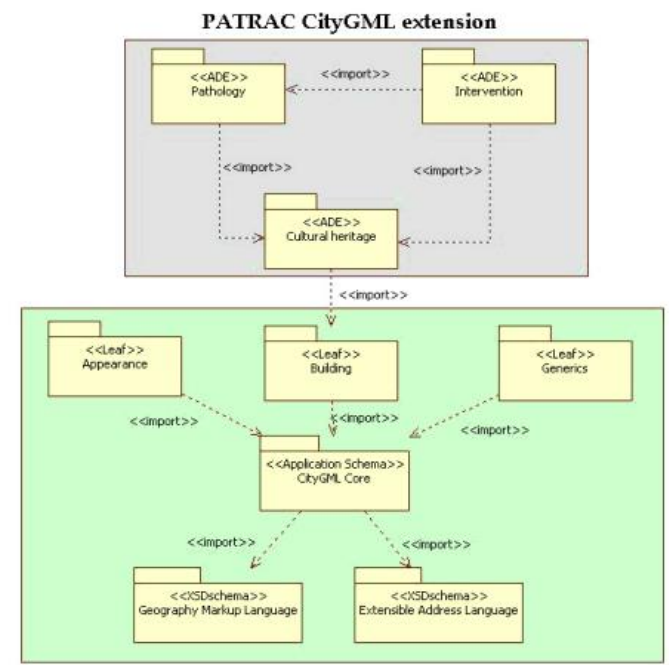

Figure 10 : Caption of a GIRAPIM CityGML extension source by F. J. Delgado et.al, (2010)

\section{CONCLUSION}

3D city model is a method to be real environment change to virtual 3D environment and can solve any problem in heritage preservation. By implement of LoDs, the 3D city model can be partition in different scale to analysis and management purpose. Meanwhile, CityGML have give beneficial for researchers to create 3D city model for its supported file. The ADE from CityGML extend have give advantages for semantically modelling detailed heritage house and the attributes that will be interoperable among many software application.

\section{ACKNOWLEDGEMENT}

Comments of referees have been very useful for improving a precedent draft. This work is partially supported by the UTM Research University Grant, Vote Q.J.130000.2527.11H78 and also thanks to Ministry of Higher Education scholarship (MOHE).

\section{REFERENCES}

H. Richards-Rissetto and R. Plessing, "Procedural modeling for ancient Maya cityscapes initial methodological challenges and solutions," Digital Heritage, Granada, 2015, pp. 85-88. doi: 10.1109/DigitalHeritage.2015.7419458.

Holland Hall, University of Exeter, 2004, https://3dwarehouse.sketchup.com, access date August 5, 2017.

J. Finat, F.J. Delgado, R. Martínez, A. Hurtado, Girapim. A 3D Information System for Surveying Cultural Heritage Environments, 2010, International Archives of the Photogrammetry, Remote Sensing and Spatial Information Sciences, Volume XXXVIII-4/W15.

Löwner. M.-O., Benner. J., Gröger. G. \& Häfele. K.-H. (2013): New Concepts for Structuring 3D City Models - an Extended Level of Detail Concept for CityGML Buildings. In: B. Murgante et al. (Eds.): ICCSA 2013. 
Nazrita Ibrahim, Khairul Azhar Azmi, Faridah Hani Mohamed Salleh \& Yussof, S. 2009. Cultural Heritage Preservation : 3D Modelling of Traditional Malay House using Hidden Surface Removal Approach. International Conference on Software Engineering and Computer Systems 2009 (ICSECS09)

R. Akmaliaa, H. Setan a, Z. Majid a, D. Suwardhi, Representing 3D Model of Building From TLS Data Scanning in CityGML, 2014, pp. 49-53, jurnal teknologi.

Romain Nouvel, Jean-Marie Bahu, Robert Kaden Jerome Kaempf, Piergiorgio Cipriano, Moritz Lauster,Karl-Hainz Haefele, Esteban Munoz, Olivier Tournair, Egbert Casper,

Development of the CityGML Application Domain Extension Energy for Urban Energy Simulation, 14th Conference of International Building Performance Simulation Association, Hyderabad, India, Dec. 7-9, 2015.

Safwan.M and Hariz.M, 3D Kampung Morten House Walkthrough, 2016, Graphic Design Diploma UiTM Lendu.

Shi $\mathrm{Pu}$ and George Vosselman, Refining Building Facade Models With Images, (2009) IAPRS, Vol. XXXVIII, Part 3/W4 , Paris, France.

Surendra Pal Singh, Kamal Jain and V. Ravibabu Mandla, Virtual 3d City Modeling: Techniques and Applications, Volume XL-2/W2, ISPRS 8th 3D GeoInfo Conference \& WG II/2 Workshop, 27 - 29 November 2013, Istanbul, Turkey.

T. H. Kolbe. 2009. "Representing and Exchanging 3D City Models with CityGML," 3D Geo-Information System. XVIII.

Vecco, M. A definition of cultural heritage: From the tangible to the intangible. J. Cult. Herit. 2010, 11, 321-324.

W N F W A Basir, H Setan, Z Majid and A Chong, Geospatial database for heritage building conservation, 2014, IOP Conference Series: Earth and Environmental Science, Volume 18. 